Sharif University of Technology
Scientia Iranica
SCIENTIA
IRAN I CA

\title{
Kinetics of reduction and oxidation reactions during pyrometallurgical metal extraction
}

\author{
S. Brožováa ${ }^{\text {, S. Jursová }}{ }^{\mathrm{b}, *}$, P. Pustějovská ${ }^{\mathrm{b}}$ and J. Bilík ${ }^{\mathrm{b}}$ \\ a. Faculty of Metallurgy and Materials Engineering, VSB-Technical University of Ostrava, 17. listopadu, 708 33 Ostrava, Czech \\ Republic. \\ b. Centre ENET, VSB-Technical University of Ostrava, 1\%. listopadu, 70833 Ostrava, Czech Republic.
}

Received 12 February 2016; received in revised form 3 June 2016; accepted 23 July 2016

\author{
KEYWORDS \\ Pyrometallurgical \\ extraction; \\ Testing of reduction; \\ Kinetic model; \\ Iron oxides; \\ Chemistry engineering \\ application.
}

\begin{abstract}
The article deals with a sophisticated approach to the study of basic kinetic dynamic process in metal production. It is concerned with three agendas: study of reduction reactions of iron oxides and carbon as reducing agents with secondary created oxides; study of the effect of catalyst occurrence on the reaction space; study of the effect of variable temperature and pressure gradients on the processes. The main experiments were carried out in the newly established Laboratory for Research on High Temperature Properties equipped with testing setup and upgraded with interpretive model system, enabling a generalization of experimentally obtained information to theoretical conclusions about processing of non-standard alternative and waste materials.
\end{abstract}

(C) 2017 Sharif University of Technology. All rights reserved.

\section{Introduction}

Available information on reducibility of iron ores and sinters, as well as knowledge of coke reactivity, has not sufficiently been used in blast furnace routine so far. The principal relation between reducibility and specific coke consumption is monitored only in qualitative explication. Mathematically statistical analysis carried out in the past on this section of blast furnace process showed considerable differences among individual blast-furnace plants, resulting in mistrust of adequacy of statistic quantitative relations among ore reducibility, coke reactivity, and its specific consumption $[1,2]$.

Parameters of a statistic relation vary not only under influence of blast furnace construction, its operation, charge abundance, etc., but also as a result of variable persistence (stay) of charge in the area under $1000^{\circ} \mathrm{C}$ which bears a proportion to the rate of charge fall in the furnace, and consequently to the appropriate heat intensity [3].

\footnotetext{
*. Corresponding author.

E-mail address: simona.jursova@vsb.cz (S. Jursová)
}

At present, it is known that there is a complete number of methods for calculation of carbon-specific consumption. Nevertheless, they all have one common fault based on disobedience to physically chemical properties of processed ores and coke as well as to leaving out of a period of charge persistence in the area under approximately $1000^{\circ} \mathrm{C}$ [4]. Some methods of heat balance prognosis rely on presumption, of course, of chemical reactions corresponding to equilibrium state which, however, cannot be obtained in blast furnace routine. In French research institute IRSID., Rist drew a diagram (Figure 1) inducing theoretical carbon consumption under equilibrium state on the basis of laboratory study of chemical processes at blast furnace and heat balance of furnace bottom zone $[5,6]$. The following studies, performed at Institute of Chemical Process Fundamentals, Czech Academy of Science, Research Institute of Iron Metallurgy and at Centre ENET VSB-Technical university of Ostrava, were concentrated on diagram extension [7] by application of laboratory-rated reducibility when reactions in blast furnace stack are considerable under real conditions and equilibrium state is not obtained. Application 


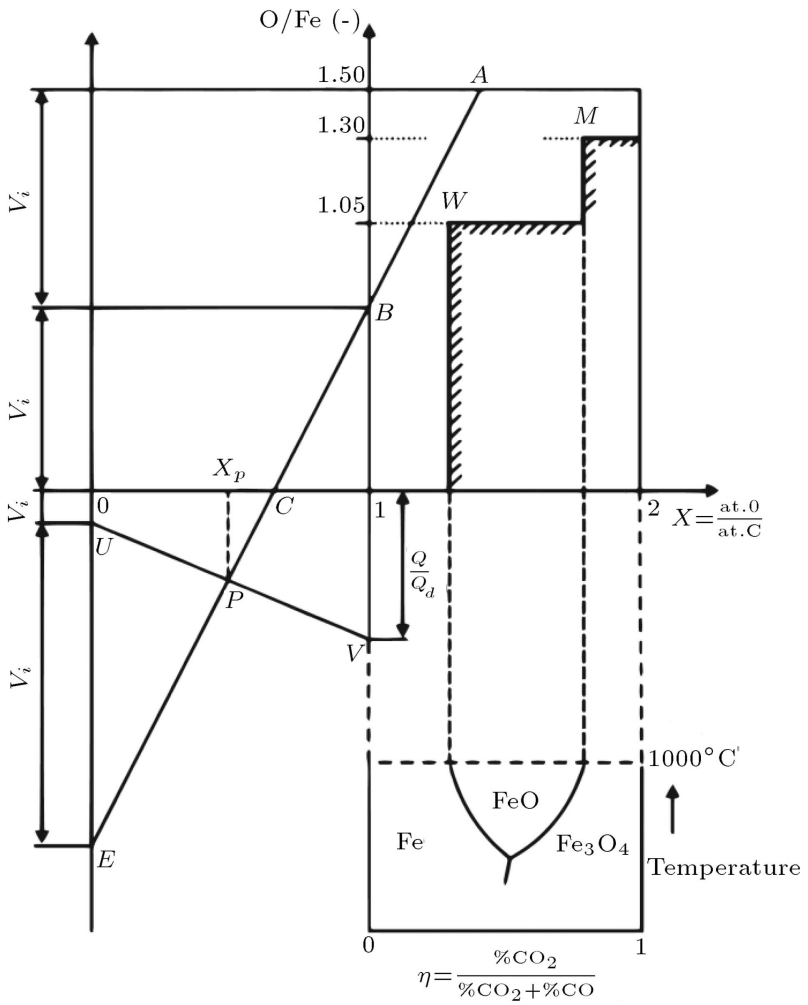

Figure 1. Rist's diagram for graphical evaluation of reduction and heat work of blast furnace.

of approaches of chemical engineering has enabled researchers to create a reduction kinetic model based on charge reducibility; it represents a necessary step for deduction (prediction) of quite possible minimum coke consumption.

\subsection{Kinetic interpretation model}

The first part of kinetic interpretation model includes calculating (quasi) velocity kinetic constants of successive reduction reactions of iron oxides at blast furnace stack and following calculation of deviation of charge oxidation grade, $\omega$, from equilibrium state [8]. For this purpose, results of reducibility laboratory tests, currently carried out in laboratory of ENET Institute of VŠB-TU Ostrava, are used. Sinter reducibility is determined based on the real sample of medium grain so that test outputs (kinetic curve of oxygen degradation from iron oxides during reduction) can correspond to real charge conditions at blast furnace.

By following the laboratory measurements of reducibility carried out along with the subsequent elaboration of extensive calculations, it was found out that the relation between $\omega$ deviation from Rist's diagram (Figure 2) and carbon-specific consumption expressed by a number of moles per iron atom is nonlinear in the assigned period of charge persistence; based on real limits, it can be approached with sufficient accuracy of square function [9].

As the number of $\mathrm{CO}$ moles per $\mathrm{Fe}$ atom is a

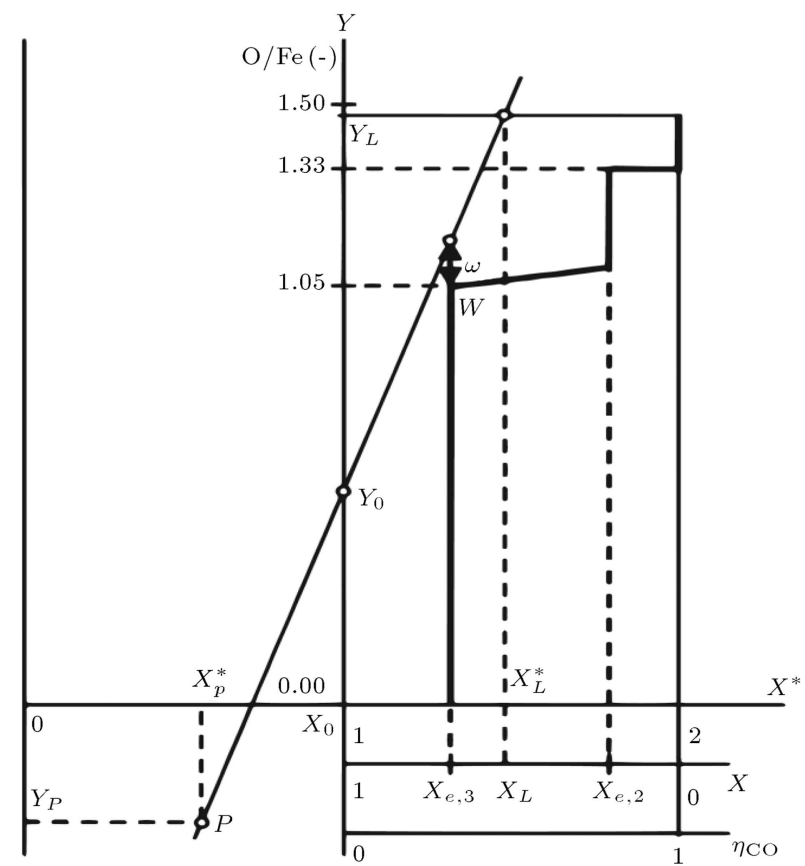

Figure 2. Importance of $\omega$ deviation in Rist's diagram [8].

direction of Rist's diagram operation line, it is possible to express $\omega$ deviation for carbon-specific consumption $(C S)$ by the following formula:

$$
\omega=a_{0}+a_{1} \cdot C S+a_{2} \cdot C S^{2},
$$

where $\omega$ is the deviation equal to the difference of real consumption of coke carbon and its theoretical minimum consumption corresponding to equilibrium state; $C S$ is the direction of operation line; and $a_{0}, a_{1}$, and $a_{2}$ are square function constants.

Furthermore, based on Rist's diagram (Figure 3), for the assigned composition of pig iron and heat consumption over $950^{\circ} \mathrm{C}$, including heat loss, a fixed point laying on operation line is determined, and its location together with change of direction of this line is not changed (Figure 4).

Therefore, other formulas corresponding to these conditions can be compiled as follows:

$$
\begin{aligned}
& \omega+1.05=C S \cdot R_{S}+q, \\
& P_{y}=C S \cdot P_{X}+q,
\end{aligned}
$$

where $R_{S}$ is $x$-coordinate of $W$ point corresponding to oxidation grade of reducing gas during indirect wïstit reduction under equilibrium state; $q$ is section designated by operation line on $y$ axis $\left(Y_{0}\right.$ in Figure 2); and $P_{x}$, and $P_{y}$ are coordinates of $P$ point.

With the solution of the mentioned formulas, direction of real operating line can be calculated, which goes through $P$ point and touches envelope curve. Envelope curve is obtained by infinite, different 


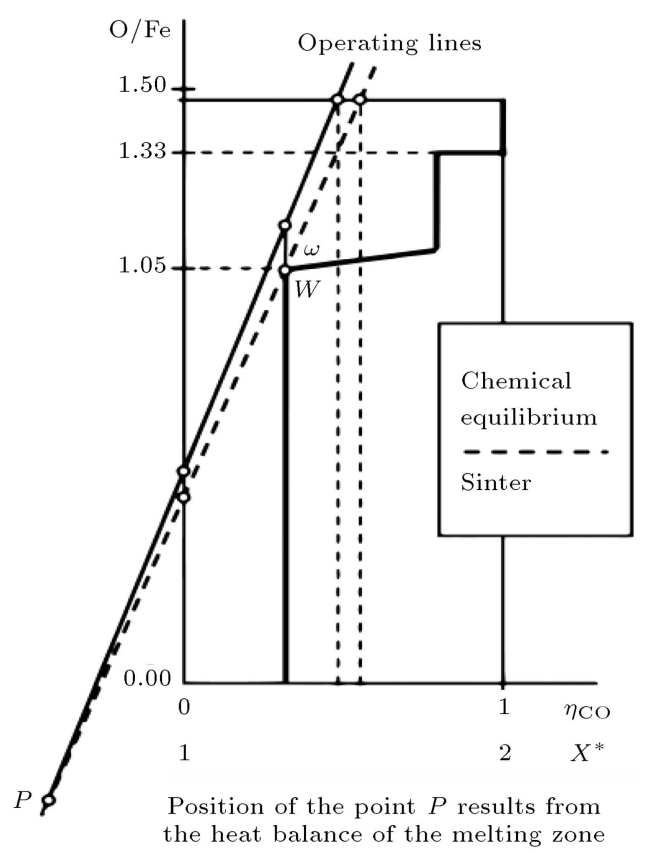

Figure 3. Importance of $P$ point in Rist's diagram [8].

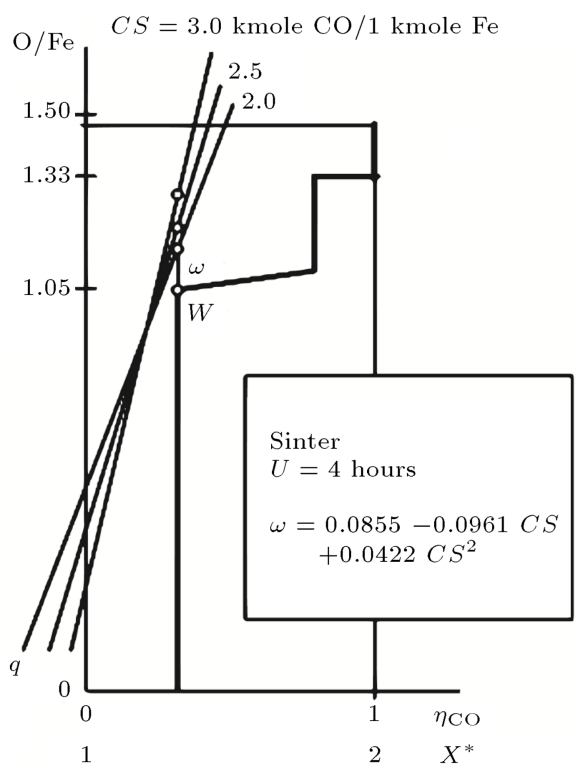

Figure 4. Set of operation lines [8].

directions of the given sinter reducibility [1]. Derived equation of operating line direction is as follows (4):

\section{$C S$}

$=\frac{R_{S}-P_{x}-a_{1}-\sqrt{\left[\left(R_{s}-P_{x}-a_{1}\right)\right]^{2}-4 a_{2}\left(1.05+a_{0}-P_{y}\right)}}{2 a_{2}}$.

To determine direction of real operating line, it is necessary to know the position of $P$ point $=\left(P_{x}, P_{y}\right)$ which characterizes the reducibility of appropriate sinter, and it is specified by heat balance of blast furnace bottom zone, the use of reducing gas under equilibrium conditions, and $a_{0}, a_{1}$, and $a_{2}$ coefficients of square functional dependence, $\omega-C S$.

In this way, deduced operating line indicates real carbon/coke/consumption including other characteristics of blast-furnace process, such as composition of charge gas, grade of $r_{d}$ wüstit direct reduction, etc.

Complying with real charge reducibility through introducing $\omega$ parameter into construction of real operating line enables a significant extension of informational contribution to Rist's diagram. The parameters such as heat amount for reduction of accompanying elements, iron and slag enthalpy above $950^{\circ} \mathrm{C}$, heat losses at blast furnace bottom part are possible to be continuously counted for real blast furnace by application of parameter $\omega$ into construction of real operating line.

Value of $\omega$ parameter, specifying approximation size of operating line towards thermodynamic $W$ point, is a purposeful complex characteristic of charge reducibility [10]. Lower value of $\omega$ parameter means better reducibility. Size of $\omega$ parameter determined from experimental laboratory tests can be compared with the value of $\omega$ derived from IS on blast furnace operation for the purposes of offline technology control.

\subsection{Specification of charge persistence period}

Another problem being solved is specifying a period of charge persistence $(U)$ in the area under the temperature of $950^{\circ} \mathrm{C}$ as exact as possible. Preliminary calculations showed that persistence period, $U$, influences coke consumption much more during processing sinter of low reducibility because $U$ increasing from 2 to 3 hours will reflect coke consumption by the decrease of approximately $35 \mathrm{~kg} . \mathrm{t}^{-1}$ of pig iron. Further increase of $U$ period to 4 hours reduces coke consumption only by approximately $18 \mathrm{~kg} . \mathrm{t}^{-1}$ of pig iron. When sinter reducibility is high, the influence of persistence period on coke consumption is markedly decreased. The increase of persistence period from 3 to 4 hours brings coke saving of only $5 \mathrm{~kg} . \mathrm{t}^{-1}$. An example of graphic realization of the influence of $U$ persistence period on the position of regressive curve, $\omega-C S$, is shown in Figure 5 .

Practical verification of the proposed model of calculation of carbon-specific consumption, including verification of the range of heat intensity variation and heat losses under real conditions of individual blast-furnace plants, enables researchers to determine coke consumption at blast furnace without correction coefficients used so far, with knowledge of reducibility of processed compounds of blast-furnace charge and also prognosis of coke consumption for the purposes of control of blast-furnace heat state. The assumed specification of calculation of carbon-specific consumption for balance and planning savings corresponds to reducibility of processed charge (sinter) and heat inten- 


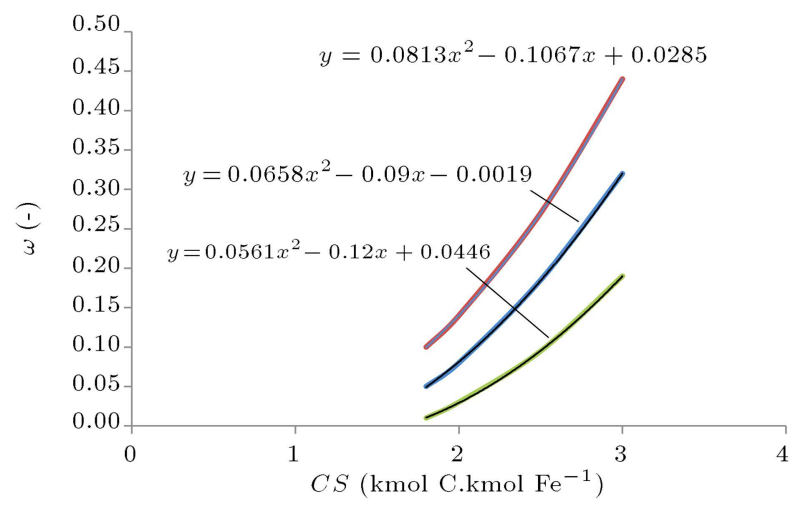

Figure 5. Statistic relationship between a model determined by omega parameter and specific-carbon consumption at different process intensities; green curve $U=4$ hours, blue curve $U=3$ hours, and red curve $U=2$ hours.

sity. Relevant characteristics derived from laboratory reducibility tests, e.g. coefficients of square function of $\omega-C S$ dependence, significantly extend sinter evaluative criteria. The use of specified interpretation model under the condition of permanent and regular measurements of reducibility of blast-furnace charge (sinter, waste metal bearing materials) enables application of interpretation model for operative production control aiming to minimize coke/fuel/consumption at blast furnaces $[2,11]$.

Such realization should bring about a significant decrease of the existing heat reserve at blast-furnace process, and it represents a remarkable economic as well as energetic effects.

\section{Experimental data}

\subsection{Reduction kinetic model for laboratory tests interpretation}

Model considerations resulted, at first, only from idealized conception of indirect reduction by carbon monoxide at the isothermal area of the ore charge column. So, the general model concept resulted from the conception of ore charge and reduction of gas counter-flow in the area of vertical cylinder with a base of unit area, Figure 6 .

Movement of both phases-ore charge and reducing gas-occurs in cylinder axis direction against each other. Cylinder axis is parallel to $z$-coordinate. Gas entering the cylinder is reduced on the horizon with coordinate $z=0$.

On the contrary, mixture of iron oxides $\left(\mathrm{Fe}_{2} \mathrm{O}_{3}\right.$ and $\mathrm{Fe}_{3} \mathrm{O}_{4}$ ) enters the cylinder on $z=L$ horizon, and step-by-step reduction occurs according to following relation:

$$
\mathrm{Fe}_{2} \mathrm{O}_{3} \stackrel{k_{1}}{\rightarrow} \mathrm{Fe}_{3} \mathrm{O}_{4} \stackrel{k_{2}}{\rightarrow} \mathrm{FeO}_{1.05} \stackrel{k_{3}}{\rightarrow} \mathrm{Fe},
$$

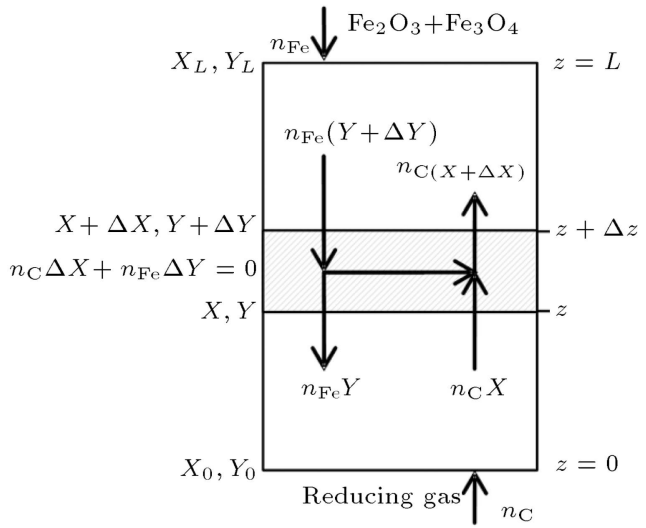

Figure 6. Model diagram of charge and gas counter-flow [8].

$$
\begin{gathered}
i=1 \quad i=2 \quad i=3 \quad i=4, \\
\mathrm{Fe}_{2} \mathrm{O}_{3} \rightarrow \mathrm{Fe}_{3} \mathrm{O}_{4} \rightarrow \mathrm{FeO}_{1.05} \rightarrow \mathrm{Fe} .
\end{gathered}
$$

Formularization of material balance of individual oxides at contemplated elementary cylinder with $\Delta z$ height under unstable state is as follows:

$$
\begin{gathered}
G_{i}(z+\Delta z)-G_{i}(z)+G_{(i-1, i)(z)-G_{i, i+1}(z)} \\
=\frac{M_{i}(t+\Delta t)-M_{i}(t)}{\Delta t}
\end{gathered}
$$

where input as well as output flows and $\mathrm{Fe}$ accumulation in " $i$ " form are given as:

$$
\begin{aligned}
& G_{i}=\rho_{p} \cdot C_{i} \cdot v_{p}, \\
& M_{i}=\rho_{p} \cdot C_{i} \cdot(1-\varepsilon) \cdot \Delta z,
\end{aligned}
$$

where:

$C_{i} \quad$ Fe concentration in the mould as well as fraction of all $\mathrm{Fe}$ in charge

$G_{i} \quad$ Fe flow in the mould as well as to the elementary cylinder

$M_{i} \quad$ Fe accumulation in the mould as well as in the elementary cylinder

$G_{i, i+1} \quad$ Fe amount in the mould as well as reduced amount of Fe in mould $i+1$

$v_{p} \quad$ Descending charge rate

$\varepsilon \quad$ Ore charge pore space

$\rho_{p} \quad$ Share of all iron in ore charge volume unit

In Eq. (6), $G_{0,1}-G_{4,5}=0$ is applied.

Reduction rate:

$$
G_{j, j+1}=\rho_{p} k_{i} C_{j}\left(X-X_{r, j}\right)(1-\varepsilon) \cdot \Delta z,
$$

with $j=i-1$ or $j=i$ is proportional to the product of $k_{i}$ kinetic constant, Fe concentration in appropriate $C_{i}$ 
oxide, and difference of $\mathrm{CO}$ concentration in reducing gas in comparison with equilibrium concentration $(X-$ $\left.X_{r, i}\right)$. After limited transition made to infinitely small height, $\Delta z$, and infinitely little time, $\Delta t$, balance formula can be derived for $i$ - $n$-oxide:

$$
\begin{aligned}
\frac{\partial C_{i}}{\partial t} & -\frac{v_{p}}{1-\varepsilon} \cdot \frac{\partial C_{i}}{\partial z}=-k_{i} C_{i}\left(X-X_{r, i}\right) \\
& +k_{i-1} C_{i-1}\left(X-X_{r, i-1}\right)
\end{aligned}
$$

where:

$v_{p} \quad$ Descending charge rate

$\varepsilon \quad$ Ore charge pore space

$\rho_{p} \quad$ Share of all iron in ore charge volume unit

For carbon monoxide, balancing of reducing gas is then defined as an iron oxidation grade in charge as follows:

$$
Y=1.5 C_{1}+1.33 C_{2}+1.05 C_{3} .
$$

Material balance in the cylinder with elementary height, $\Delta z$, considers input and output flows and accumulation of carbon monoxide. It is applied as follows:

$$
\begin{aligned}
\varepsilon \cdot \rho_{g} \frac{\partial X}{\partial z} & +v_{g} \cdot \rho_{g} \cdot \frac{\partial X}{\partial z}=(1-\varepsilon) \cdot \rho_{p} \cdot \frac{\partial Y}{\partial t} \\
& -v_{p} \rho_{p} \cdot \frac{\partial Y}{\partial z}
\end{aligned}
$$

where:

$\rho_{g} \quad$ Reducing gas density

$v_{g} \quad$ Beyond the layer speed of reducing gas

This equation supplements the equation system of $i=1, \cdots, 4$ to the complete system of partial deferential equations, which can be theoretically solved for the given initial and edge conditions. Equilibrium composition of reducing gas can be determined by thermodynamic relations. In the calculations, it was counted with the simplifications as the composition and amount of reducing gas in laboratory conditions were not completely the same as those of the real blast furnace.

Accordingly, reduction runs in 3 grades: from $\mathrm{Fe}_{2} \mathrm{O}_{3}$ to $\mathrm{Fe}_{3} \mathrm{O}_{4}$, then to $\mathrm{FeO}$, and finally to Fe. It was necessary to use kinetic constants of individual chemical reactions in equations. Edge and initial conditions of partial differential equations were determined by two tasks, as shown in Figure 7.

The first task is reduction simulation in solid layer by a great surplus of reducing gas as it conforms to ENET laboratory. Reducibility laboratory tests are realized in stagnant layer where $v_{p}=0$. In comparison with real reduction stack, the layer height of sample

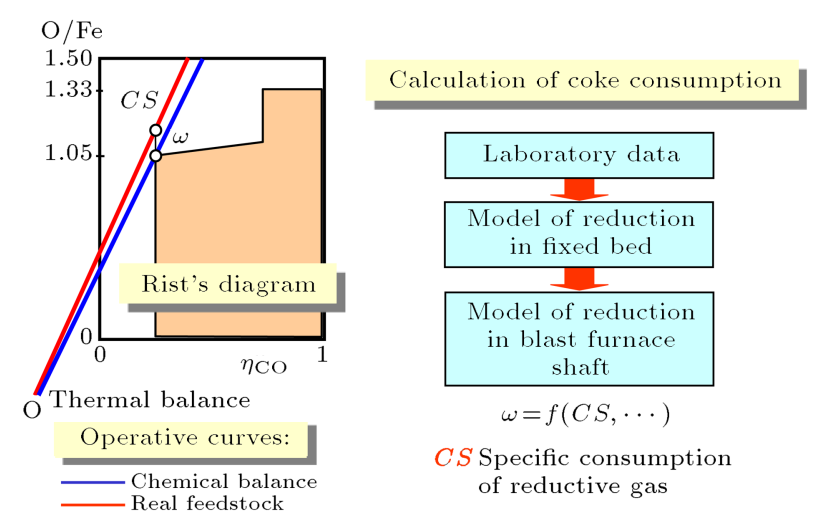

Figure 7. Using a mathematical model of counter-current flow in a blast furnace to evaluate reducibility of iron-ore-bearing raw materials.

during reducibility laboratory test is very low, and amount of reducing gas is very high considering the sample. This fact is entitled to accept the simplifying assumption that after sample height at testing report, the differences in charge oxidation grades and reducing gas are irrelevant during reduction in proper instant of time. Then, even derivation, according to the layer height, can be considered to be zero regarding the other equation terms.

In this way, a system of ordinary linear differential equations originates from a general model, which can be solved analytically. The analytic solution enables one to imply gradual changing grade of iron oxidation as a function of individual kinetic constants:

Complete solution, then, represents a formula form where there is a decline of the size of sample mass on the left side and complicated term depending on initial sample composition and kinetic constants on the right side. By using experimental data (time behaviour of sample mass decline), such kinetic constants can be found in theoretic function where theoretic time behaviour and measured time behaviour of mass decline of samples are nearly the same. These (quasi) kinetic constants of ore reduction by gas obtained from experimental data form a fundamentally new partial methodology result.

Subsequently, the principal part of reduction model represents the use in prior kinetic calculation of found (quasi) kinetic constants, $k_{1}, k_{2}, k_{3}$, for simulation of oxides' reduction course in reducing stack of aggregate for iron production. Assumption of reduction process stacionarity enabled one to eliminate derived material balances from the equations according to time [12].

In spite of this simplification, non-linearity of equation system and type of edge conditions do not enable simple analytic solution [13]. Therefore, a numerical solution using iterative methods was elaborated [2].

Entry for calculation is charge composition and mainly kinetic constants of chemical reactions derived 


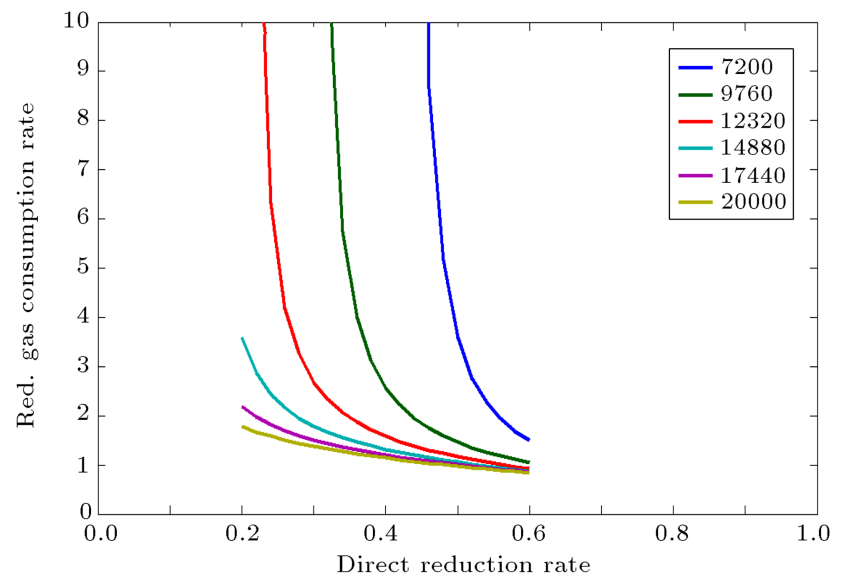

Figure 8. Dependence of reducing gas consumption on direct reduction grade at different periods of charge persistence (sec) in the area of indirect reduction for ordinary operational sinter.

from the first function. Calculation results are "practically reachable" to minimum carbon-specific consumption at blast furnace.

Nevertheless, for display clearness, it is more suitable to use coordinates which Rist has introduced for description of reduction at blast furnace (see Figure 2).

Lower value of $\omega$ parameter means a better reducibility. Parameter size $\omega$ determined from experimental laboratory tests can be compared with $\omega$ value derived from IS data on blast furnace operation.

Shift of limit kinetic curves changes their point of concurrence with heat limit and specifies optimum grade of direct reduction for different heat intensities $[14,15]$. With prolongation of period of charge persistence in the area of indirect reduction, the curve of kinetic limit gradually approaches the line of thermodynamic limit $[16,17]$, and with decrease of persistence period, the curve of kinetic limit of carbon consumption moves to higher values (Figure 8).

\subsection{Complex kinetic model of iron oxides reduction in blast furnace}

Gradually, an idea has been initiated to work out a comprehensive evaluation method which would enable one to predict capacity parameters of reduction process the same as fuel and reducing agent consumption. In practice, it means a comprehensive kinetic model of wüstite reduction at parallel coke gasification by Boudouard reaction which would upgrade the kinetic model of non-direct reduction mentioned above.

Mathematical formulation is possibly derived from material balance of each component in element space with height, $d h$, and considering all their relations, such as stechiometric ratio and balance conditions of heterogeneous mixtures, suitable kinetic formulation for considered reactions, and their application in energy and material balance. By elaboration of new variant of earlier German model of direct and non-direct reductions at VSB-Technical University, the above-mentioned results of material tests of ores and coke as kinetic characteristic were used.

The basics of the model were founded by Professor Jeschar from Technical University of Clausthal. The model involves effects of ore reducibility and coke reactivity on the course of iron ore reduction. The heat balance is a part of the model.

In the low area of reduction zone, reduction of wüstite to iron takes place in parallel to Boudouard reaction according to the reactions below:

$$
\begin{aligned}
& \mathrm{FeO}+\mathrm{CO} \leftrightarrow \mathrm{Fe}+\mathrm{CO}_{2}, \\
& \mathrm{C}+\mathrm{CO}_{2} \leftrightarrow 2 \mathrm{CO} .
\end{aligned}
$$

The derivation of model is explained in Figure 9, presenting an elemental part of volume of reactive space where coke and ores create a canal for gas flowing. It is suggested that ore and coke go down at the same speed, and wüstite does not react with solid carbon but exclusively with $\mathrm{CO}$.

Equation of material balance:

$$
\begin{aligned}
& d \dot{n}_{\mathrm{tot}}=d \dot{n}_{\mathrm{CO}}+d \dot{n}_{\mathrm{CO}_{2}}, \\
& d \dot{n}_{\mathrm{CO}_{2}}=d \dot{n}_{\mathrm{CO}_{2} \cdot o g}+d \dot{n}_{\mathrm{CO}_{2} \cdot g c}, \\
& d n_{\mathrm{CO}}=d n_{\mathrm{CO}_{2} \cdot c g}+d n_{\mathrm{CO}_{2} \cdot g o}, \\
& d n_{\mathrm{CO}_{2}}=\frac{d}{d h}\left(\frac{n_{\mathrm{tot}} \cdot p_{\mathrm{CO}_{2}}}{p_{\mathrm{tot}}}\right) d h \\
& d n_{\mathrm{CO}_{2}}=\frac{d}{d h}\left(\frac{n_{\mathrm{tot}} \cdot p_{\mathrm{CO}}}{p_{\mathrm{tot}}}\right) d h, \\
& p_{\mathrm{CO}}+p_{\mathrm{CO}_{2}}+p_{\mathrm{N}_{2}}=p_{\mathrm{tot}}=\mathrm{const}, \\
& d \dot{n}_{\mathrm{CO}_{2} \cdot o g}=-d \dot{n}_{\mathrm{CO} \cdot g o}, \\
& d \dot{n}_{\mathrm{CO} \cdot c g}=-2 d \dot{n}_{\mathrm{CO}} \cdot g c \cdot
\end{aligned}
$$

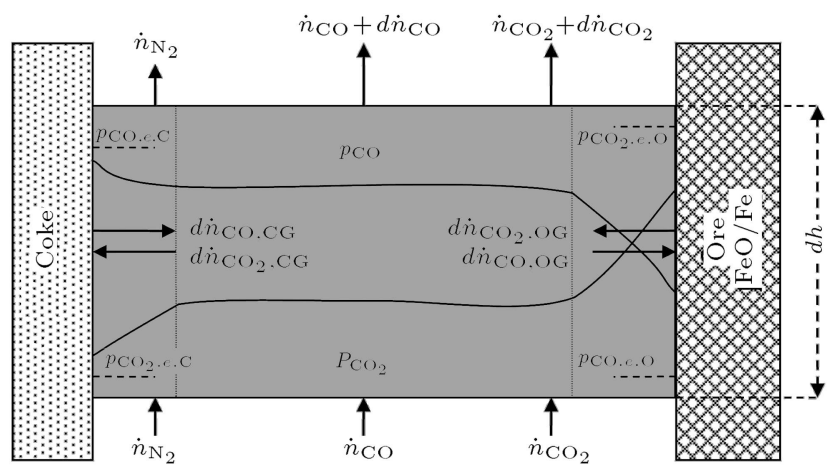

Figure 9. Basic scheme of model of wüstite reduction in the zone of Boudouard reaction. 
The balance constant, partial pressure of $\mathrm{CO}$ and $\mathrm{CO}_{2}$ of Reaction 13 on the ore surface are presented in the literature. For Boudouard reaction, the following is considered:

$$
\begin{aligned}
& K_{B}=\frac{p_{\mathrm{CO} \cdot e}^{2}}{p_{\mathrm{CO} \mathrm{O}_{2} \cdot e}}=\frac{p_{\mathrm{CO} \cdot e}}{p_{\mathrm{tot}}-p_{\mathrm{CO} \cdot e}-p_{\mathrm{N}_{2}}}, \\
& \log K_{B}=-\frac{9003}{T}+9.28
\end{aligned}
$$

From Eq. (23) the following equation is obtained:

$$
p_{\mathrm{CO} \cdot e \cdot \mathrm{C}}=\frac{-K_{B}+\sqrt{K_{B}^{2}+4 K_{B}\left(p_{\mathrm{tot}}-p_{\mathrm{N}_{2}}\right)}}{2} .
$$

For calculation of material change in ore surface, it is possible to use effective kinetic constant, $k_{3}$, from the above-mentioned model of non-direct reduction model. In comparison with the previous theoretic model, Professor Jeschar [2] presents a significant simulation of real state in industry:

$$
\begin{aligned}
\frac{d n_{\mathrm{CO} \cdot \mathrm{O}}}{d h} & =\frac{d n_{\mathrm{FeO}}}{d h}=n_{\mathrm{FeO}} k_{3}\left(P_{\mathrm{CO} \cdot e \cdot O}-P_{\mathrm{CO}}\right) \\
\frac{d n_{\mathrm{CO}_{2} \cdot \mathrm{O}}}{d h} & =\frac{d \dot{n}_{\mathrm{Fe}}}{d h}=-\frac{d \dot{n}_{\mathrm{CO} \cdot \mathrm{O}}}{d h} \\
& =-\dot{n}_{\mathrm{FeO}} k_{3}\left(P_{\mathrm{CO} \cdot e \cdot \mathrm{O}}-P_{\mathrm{CO}}\right) .
\end{aligned}
$$

The speed of Boudouard reaction is calculated by:

$$
\frac{d n_{i}}{d h}=\frac{f_{\mathrm{RES}} f_{(\mathrm{O})}}{R T} \cdot f(R) \cdot\left(P_{i \cdot e \cdot c}-P_{i}\right)
$$

where:

$\begin{array}{ll}f_{\mathrm{RES}} & \text { Function of resistance } \\ f(O) & \text { Function of reaction surface } \\ f(R) & \text { Function of degradation } \\ R & \text { Universal gas constant } \\ g & \text { Gas } \\ o c & \text { Ore } \\ c & \text { Coke } \\ e & \text { Equilibrium }\end{array}$

Above-mentioned functions, $f(O)$ and $f(R)$, rely on the type of reaction and mechanism determining the reaction total speed. This reliance is presented in
Table 1. The mechanism of Boudouard reaction depends on temperature. At $1100^{\circ} \mathrm{C}$, the total reaction speed is determined mainly by the speed of chemical reaction. The blast furnace shaft is divided into two main zones. The zone of medium temperature (Type I) and the zone of high temperatures (Type II). In the zone of medium temperatures, the total reaction speed is affected by diffusion in pores. At high temperatures, the diffusion on coke surface is the most important. In zone II, it is supposed that the limit for the total reaction mechanism is chemical reaction; to sum up the mechanisms in these two zones:

- Type I: Porous reducing agent, porous product;

- Type II: Dense reducing agent, porous product.

Flow of reactive gases in moles is possible to be expressed according to:

$$
\begin{aligned}
\dot{n}_{i} & =\frac{n}{t S}=\frac{v_{g} S \cdot t \cdot p_{i}}{t \cdot R \cdot T \cdot S}=\frac{v_{g} \cdot p_{i}}{R T} \\
& =\frac{v_{g} P_{i}}{R T} \cdot p_{\text {tot }} \rightarrow \frac{d P_{i}}{d h}=\frac{R T}{v_{g} \cdot p_{\text {tot }}} \frac{d n_{i}}{d h} .
\end{aligned}
$$

Substituting Eq. (27) into Eqs. (23)-(25) is derived from a change in gas composition in the height of reaction zone:

$$
\begin{aligned}
\frac{d P_{\mathrm{CO}_{2}}}{d h}= & \frac{R T}{V_{g} \cdot p_{\mathrm{tot}}}\left[-n_{\mathrm{FeO}} k_{3}\left(P_{\mathrm{CO} \cdot e \cdot \mathrm{O}}-P_{\mathrm{CO}}\right)\right. \\
& \left.+\frac{f_{\mathrm{REC}} f\left(\mathrm{O}_{c}\right) f\left(R_{c}\right)}{R T}\left(P_{\mathrm{CO}_{2} . e . c}-P_{\mathrm{CO}_{2}}\right)\right]
\end{aligned}
$$

Solution to Eqs. (28) and (29) brings the course of reducing gas composition and temperature along with the height of reduction space.

\subsection{Experimental testing of substandard and

\begin{tabular}{|c|c|c|c|c|c|c|c|}
\hline & & \multicolumn{6}{|c|}{ Type of reaction } \\
\hline & & \multicolumn{3}{|c|}{ Reaction I } & \multicolumn{3}{|c|}{ Reaction II } \\
\hline & & $f_{\text {RES }}$ & $f(O)$ & $f(R)$ & $f_{\text {RES }}$ & $f(O)$ & $f(R)$ \\
\hline \multirow{2}{*}{ 节 } & Chemical reaction & $K^{*}$ & $O_{i}$ & $1-R$ & $K^{*}$ & $4 \pi r_{0}^{2}$ & $(1-R)^{2 / 3}$ \\
\hline & Diffusion & $\frac{D^{p}}{r_{0}}$ & $O_{i}$ & $1-R$ & $\frac{D^{p}}{r_{0}}$ & $4 \pi r_{0}^{2}$ & $\frac{1}{(1-R)^{-3 / 2}-1}$ \\
\hline
\end{tabular} secondary waste materials}

Determination of reducibility test with classical pellets and sinter was carried out in 2014 in a number of research measurements. Average values of results [18] from these relatively larger test sets are compared with the newly-gained test results from waste briquettes in Table 2.

Testing results of waste briquette sample and pellets prepared from fine grain dusts of oxide are

Table 1. Dependence of reaction rate on reactive mechanism. 
Table 2. Summary of testing results (mutual comparison).

\begin{tabular}{clcc}
\hline Sample & Type & $\begin{array}{c}\text { Granulometry } \\
(\mathbf{m m})\end{array}$ & $\begin{array}{c}\text { Average } \\
\boldsymbol{d} \boldsymbol{R} / \boldsymbol{d} \boldsymbol{t}(\boldsymbol{\%})\end{array}$ \\
\hline 1 & Briquettes & 1 pc cylinder & 0.753 \\
2 & Pellets & $10-12.5$ & 0.93 \\
3 & Sinter & $10-12.5$ & 0.795 \\
\hline
\end{tabular}

compared with the testing results of classical sinters. The dust for briquette and pellets preparation was gained by industrial water treatment through removing heavy metals from the water. The main testing result, so called "Reducibility index" $d R / d t[\% / \min ]$, has standardly firm value with sinter samples; numeric value with dust pellets is higher. Though reducibility index with briquettes from metallic wastes showed lower values than sinter, it was nothing fundamental. Nevertheless, it is necessary to take into account that, benefiting from ISO standard determined methodology, reducibility index was developed for iron ore raw materialssinter ore, classic ore pellets. It can be used only for wastes close to their properties of classic raw materials.

Performance of experimental tests for the selected kinds of fine grain wastes in the form of pieces enabled us to obtain data of the application of model system to predict reduction processes at stack furnace.

Model prediction system, whose principle consists of the above-described reduction kinetic model, was designed by experts from VŠB-Technical university of Ostrava to such an extent that it can be applied even to multi-component charge: Meaning that the charge is composed of basic sinter and additional substrates. This fact creates a basis for prediction of quantitative evaluation of influence of fine grain wastes in the form of pieces. Concrete example is briquettes and pellets testings produced from metallurgic dusts and wastes due to examination of their suitability for adding them to iron ore blast-furnace charge or to charge them during processing at other stack aggregates.

Composite authors of the presented article suggested a programme with inputs through suitable dialog boxes. The method of entering proper experimental data (gained by test) enables a number of options and prediction calculations "made-to-measure" and even testing of metallic wastes in the form of pieces. Obtained programme outputs are applied in the following text during model interpretation of testing results of wastes in the form of pieces and impact prognosis of their addition.

\section{Results and discussion}

Calculated output data represent change of concentration of individual iron oxides and change of charge oxidation grade as well as gas oxidation grade during the decline in the area of indirect reduction at the stack. Figure 9 shows graphic illustration of the mentioned changes for sinter.

Indirect reduction kinetic model at the stack can be applied even to multi-component iron ore charge. Dialog box enables the entering process of the principal reduction characteristics of evaluated charge components which represent (quasi) kinetic constants of the selected charge components.

In the particular case, it is concerned with ordinary sinter and briquettes from dusts. When model calculations are carried out, then complete reduction course of the dependence on share of both examined components in charge can be reviewed from graphic representation in 3D diagram. Figure 10 shows FeO reduction course. Intersection of $\mathrm{FeO}$ concentration curve area with the vertical area, characterizing completion of indirect reduction (relative height of indirect reduction area $=0$ ), indicates which $\mathrm{FeO}$ share still remains to be reduced by the form of direct reduction. Comparing graphic course of $\mathrm{FeO}$ concentrations of both mixtures in Figure 11 (sinter-briquettes), it appears that the influence of briquette addition on reducibility of the whole mixture is quite small, and it does not considerably influence reduction course.

Testing of waste briquettes as well as specially prepared pellets from sinter dusts generally brought satisfying results. Reducibility index value of these materials is similar to substantial standard of sinter from Ostrava metallurgical plants. Considering the reducibility index value of evaluated briquettes, it does not have much effect on the total charge reducibility with regard to presumed lower share in the charge though (Figure 11). From the point of view of reducibility, it can be stated that the tested waste briquettes as well as oxiding pellets from sinter dusts are suitable charge additions both for the present blast furnaces and other reduction aggregates.

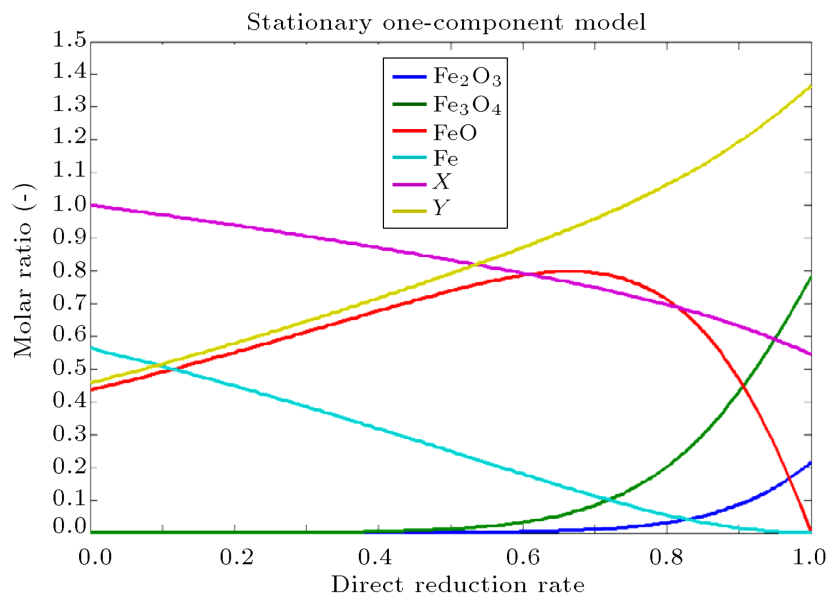

Figure 10. Concentration profiles down the height of reduction area at the stack furnace for sinter. 


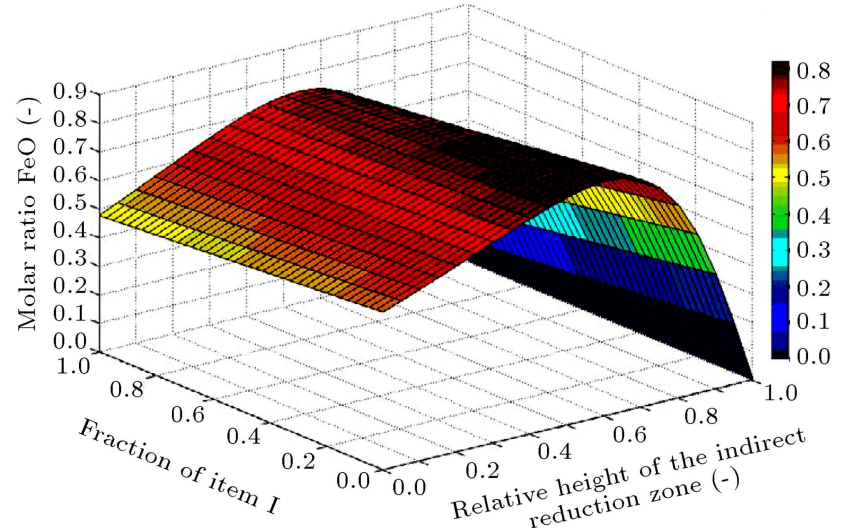

Figure 11. Course of $\mathrm{FeO}$ reduction process with mixture of sinter and briquettes in $3 \mathrm{D}$ projection.

\section{Conclusion}

In this article, we describe the principle and laboratory equipment for measuring the reductibility of the blast furnace burden, the procedure for calculating the kinetic constants of the oxidation rate of the iron oxides in this burden, and the method of calculating the composition of the charge and gas after reduction of the counterflow which are used, in the case of blast furnaces, for calculating the specific consumption of carbon. The procedure is based on mathematical modelling used in this case for processing the experimental data. The derived criteria are characterised more accurately than those used in the past; the reductibility of the burden can be used for analytical calculations of the output parameter and the consumption of the reduction agent, so it can be verified by examining the course of the blast furnace process $\left(\omega, Y_{0}, C S\right)$.

Testing of waste briquettes as well as specially prepared pellets from sinter dusts generally brought satisfying results. Reducibility index value of these materials is similar to substantial standard of sinter metallurgical plants.

\section{Acknowledgement}

This paper was conducted within the framework of the project LO1404: Sustainable development of ENET Centre.

\section{Nomenclature}

$\dot{\eta}_{i} \quad$ Flow rate in $k$ moles of component $i$ $\left(\mathrm{CO}, \mathrm{CO}_{2}, \mathrm{~N}_{2}, \mathrm{FeO}, \mathrm{Fe}, \mathrm{C}\right)$

$p_{i} \quad$ Partial pressure in $\mathrm{Pa}$ of component $i$ $\left(\mathrm{CO}, \mathrm{CO}_{2}, \mathrm{~N}_{2}\right)$

$P_{i} \quad$ Relative partial pressure of component $i\left(\mathrm{CO}, \mathrm{CO}_{2}, \mathrm{~N}_{2}\right)$

$K_{B} \quad$ Balance constant of Boudouard reaction

$K_{o} \quad$ Balance constant of reduction $\mathrm{FeO}$
$C_{i} \quad$ Molar heat capacity of component $i$ $\left(\mathrm{CO}, \mathrm{CO}_{2}, \mathrm{~N}_{2}, \mathrm{FeO}, \mathrm{Fe}, \mathrm{C}\right)$

$x \quad$ Height in reaction space

Indexes

$o \quad$ Ore

c Coke

e Balance state

\section{References}

1. Babich, A., Senk, D., Gudenau, H.W. and Mavrommatis, K.Th., Ironmaking, RWTH Aachen University, 1st Edn. pp. 36-87, Department of Ferrous Metallurgy, Wissenschaftsverlag Mainz in Aachen, Germany (2008).

2. Hauck, T., Hillmann, C. and Bartusch, H. "New ways for improvement of blast furnace process", [Neue Wege für die verbesserte Prozessanführung am Hochofen], BFI Kolloguium, Düsseldorf, Germany, pp. 86-95 (2008).

3. Czeslik, C., Seemann, H. and Winter, R., Basiswissen Physikalische Chemie, 2006. 3rd Edn. pp. 45-56, Studienbucher Chemie. Dortmund, Germany (2006).

4. Janowski, J., Lendzki, A., Klimcyzk, H. and Sadowski, A., Processes of Iron Oxides Reduction (Polish), 2nd Edn. pp. 23-35, Wydawnictwo AGH, Krakow, Poland (1989).

5. Rist, A. and Meysson, N. "Graphical analysis of possibilities for decrease on reducing agent consumption in blast furnace for various temperatures (French)", Revue de Métallurgie, 2, pp. 121-145 (1964).

6. Le Coore, C. "Mathematical model of countercurrent reduction of iron oxides at sintering (French)", C.I.I., 34(1), pp. 3-22 (1977).

7. Ti̊ma, J., Drabina, J., Stanek, V. and Moravec, P. "Using a mathematical model for evaluating the reducibility of iron bearing raw materials (Czech)", Hutnicke Listy, 43(4), pp. 228-233 (1988).

8. Pustějovská, P., Ti̊ma, J., Staněk, V., Křištál, J., Jursová, S. and Bilík, J. "Using a mathematical model of counter-current flow in a blast furnace to evaluate reducibility of iron-ore-bearing raw materials", Steel Research International, 86(4), pp. 320-328 (2015).

9. Knepper, M., Babich, A. and Senk, D. "Kinetic reaction of reducing agent in blast furnace and meltingaggregates (German)", 27, Aachener Stahlkolloquium, Eurogress Aachen, Germany, pp. 85-96 (2012).

10. Džupková, M., Fröhlichová, M., Legemza, J. and Findorák, R. "Evaluation of selected technological and ecological parameters of sinter production", Acta Metallurgica Slovaca, 17(4), pp. 269-275 (2011).

11. Jeschar, R. and Bittner, H.G. "A theoretical model coupling kinetics of ore reduction and coke gasification in blast furnace", Proceeding of the European Ironmak- 
ing Congress in Aachen, 3, Dússeldorf, Germany, pp. 991-997 (1986).

12. Bilík, J., Sch"utzenhöfer, W. and Lužný, R. "Analytical models of blast furnace process in current blast furnace practice (Czech)", Hutnické Listy, 54(7-8), pp. 13-16 (1999).

13. Pustějovská, P., Jursová, S. and Brožová, S. "Determination of kinetic constants from tests of reducibility and their application for modelling in metallurgy", Journal of the Chemical Society of Pakistan, 35(3), pp. 565-569 (2013).

14. Bilík, J., Schützenhöfer, W. and Hiebler, H. "Use of mathematical modeling for reduction processes in metallurgy (German)", 142(5), pp. 166-169 (1998).

15. Mandal, G.K., Sau, D.C. and Bandyopadhyay, D.A. "Steady state thermal and material balance model for an iron making blast furnace and its validation with operational data", Transactions of the Indian Institute of Metals, 67(2), pp. 209-221 (2014).

16. Moore, W.J., Bases of Physical Chemistry (German), 1st Edn., pp. 24-31, de Gruyter, Berlin, Germany (1990).

17. Wedler, G., Book of Physical Chemistry (German), 5th Edn., pp. 48-62, Wiley-VCH, Weinheim, Germany (2004).

18. Konstanciak, A. "High temperature investigation of the properties of blast furnace coke", Metalurgija, 42(4), pp. 235-237 (2003).

\section{Biographies}

Silvie Brožová was born in Ostrava, Czech Republic in 1973. She obtained her habilitation in Metallurgical Technology in 2015 and, since that time, she has been working as an Associate Professor at VSB, the Technical University, and in a research team at the Regional Material and Research Centre. Her main research interests include plasma technology in metallurgy for metallurgical waste processing.

Simona Jursová was born in Cesky Tesin, Czech Republic in 1984. She obtained her $\mathrm{PhD}$ degree in 2011; currently, she works as a junior researcher in research centre ENET in Ostrava, Czech Republic. Her research activities are focused on reduction processes in iron-making. She studies iron materials reducibility and disintegration in different reduction atmosphere and temperature.

Pavlína Pustẽjovská was born in Ostrava, Czech Republic in 1972. She obtained her habillitation in Metallurgical Technology in 2015. She focused on application of non-traditional alternative fuels during pig iron production and has had experience with research work in regional research centres, focusing on alternative fuels, deoxidizing agents, and closedcycle technology development in metallurgy. Currently, she is working as an Associate Professor at VSB, the Technical University, including research activities in Centre ENET.

Jiří Bilík was born in Ostrava, Czech Republic in 1945. He obtained his MS degree in Metallurgy in 1968 and became a Professor in the field of Metallurgy, specializing in alternative fuels for pig iron production in 2003. From 2010 - 2014, he was the Head of the research program 01 in Centre ENET, focusing on alternative methods of metal production. 